\title{
Variation of Photosynthesis, Fatty Acid Composition, ATPase and Acid Phosphatase Activities, and Anatomical Structure of Two Tea (Camellia sinensis (L.) O. Kuntze) Cultivars in Response to Fluoride
}

\author{
L. X. Wang, ${ }^{1,2}$ J. H. Tang, ${ }^{2}$ B. Xiao, ${ }^{1}$ Y. J. Yang, ${ }^{3}$ and J. Liu' \\ ${ }^{1}$ College of Horticulture, Northwest A\&F University, Yangling, Shaanxi 712100, China \\ ${ }^{2}$ College of Life Science and Technology, Yangtze Normal University, Fuling, Chongqing 408000, China \\ ${ }^{3}$ Tea Research Institute, Chinese Academy of Agricultural Sciences, Hangzhou, Zhejing 310013, China \\ Correspondence should be addressed to B.Xiao; binx50@yahoo.com
}

Received 5 March 2013; Accepted 16 June 2013

Academic Editors: R. Çakmakçi and S. D. Yeh

Copyright (c) 2013 L. X. Wang et al. This is an open access article distributed under the Creative Commons Attribution License, which permits unrestricted use, distribution, and reproduction in any medium, provided the original work is properly cited.

\begin{abstract}
The changes of photosynthetic parameters, water use efficiency (WUE), fatty acid composition, chlorophyll (Chl) content, malondialdehyde (MDA) content, ATPase and acid phosphatase activities, fluoride (F) content, and leaf anatomical structure of two tea cultivars, "Pingyangtezao" (PY) and "Fudingdabai" (FD), after F treatments were investigated. The results show that net photosynthetic rate $\left(P_{n}\right)$, stomatal conductance $\left(g_{s}\right)$, and transpiration rate $(E)$ significantly decreased in both cultivars after $0.3 \mathrm{mM}$ F treatment, but FD had higher $P_{n}, g_{s}$, and WUE and lower $E$ than PY. Chl content in PY significantly decreased after 0.2 and $0.3 \mathrm{mM} F$ treatments, while no significant changes were observed in FD. The proportions of shorter chain and saturated fatty acids increased and those of longer chain and unsaturated fatty acids decreased in both cultivars under F treatments. The contents of MDA increased after F treatments but were higher in PY than in FD. In addition, F treatments decreased the activities of ATPase and acid phosphatase and increased F content in both cultivars; however, compared with PY, FD showed higher enzymatic activities and lower F content in roots and leaves. Leaf anatomical structure in FD indicated that cells in leaf midrib region were less injured by $\mathrm{F}$ than in PY.
\end{abstract}

\section{Introduction}

$\mathrm{F}$ is naturally present in sediments and soils, with a concentration range from 150 to $400 \mathrm{mg} \mathrm{kg}^{-1}$ and generally in forms of various insoluble compounds with elements such as calcium, aluminum, and silicon [1]. F is released into water, air, and soil through natural weathering and human activities, such as coal combustion and discharges of industrial water and industrial waste $[2,3]$. Phosphate fertilizer and F-containing pesticides are additional sources releasing $F$ into the environment $[4,5]$. Trace amount of $\mathrm{F}$ is beneficial for the growth of teeth and bones in mammals, with its recommended upper limit at $1.5 \mathrm{mg} \mathrm{kg}^{-1}$, but excessive $\mathrm{F}$ intake has adverse effects $[6,7]$. F-containing foods, drinking water, and especially tea are the major sources of $\mathrm{F}$ accumulation in humans $[8,9]$.
Tea as the most popular beverage crop in China can selectively absorb $\mathrm{F}$ from soil and thus results in higher F concentrations in tea leaves, compared with other plants including pine (Pinus banksiana), subterranean clover (Trifolium subterranean), cocksfoot (Dactylis glomerata), scotch thistle (Onopordum acanthium), and Salicornia brachiate $[10,11]$. Some studies have investigated the effects of $\mathrm{F}$ on the physiological metabolism of tea plants, such as toxic symptoms [12], growth [13], photosynthesis [14], respiration [15], and carbohydrate metabolism [16]. However, few studies have investigated varietal difference of tea plants on tolerance to $\mathrm{F}$.

Previous studies showed that the concentrations of $\mathrm{F}$ in tea plants are significantly different from variety to variety, even for those living in the same natural environment [1719]. Because of the long-term allogamy, tea plants might have 
a wide range of genetic backgrounds that affect the absorption and accumulation of F $[20,21]$. In this study, two tea varieties were selected and investigated to further clarify the varietal tolerance and physiological response of tea plants to F. The results may help screen the low $\mathrm{F}$ variety for tea planting.

\section{Materials and Methods}

2.1. Plant Materials and Growth Conditions. One-year-old tea plants derived from rooted cuttings of two cultivars of Camellia sinensis, "Pingyangtezao" (PY) and "Fudingdabai" (FD) were used in this study. Both PY and FD are traditional cultivars possessing good agronomic characters, and were provided by Tea Experimental Station of Northwest A\&F University. The plants were grown in black plastic containers $(37 \times 28 \times 8 \mathrm{~cm})$ each containing $1,000 \mathrm{~mL}$ of one-fifth strength Hoagland solution [22] for a week, and then transferred to half-strength Hoagland solution. The containers were placed in a growth chamber set at $70 \%$ relative humidity, $25 / 20^{\circ} \mathrm{C}$ (day/night), and a $12 \mathrm{~h}$ photoperiod with photon irradiance of $200 \mu \mathrm{mol} \mathrm{m} \mathrm{s}^{-1}$ [23]. The solutions were aerated continuously and replaced weekly. Three containers, each containing 35 plants, were used for each treatment. Ammonium fluoride of $0,0.1,0.2$, and $0.3 \mathrm{mM}$ were added separately to the solutions. After incubation for 1,3 or 14 days, the plants were collected for the following physiological analyses.

2.2. Photosynthetic Capacity. A Li-6400 portable photosynthesis system (Li-Cor, Nebraska, USA) was used to measure photosynthetic capacity of the third leaves after F treatments. Measurements were carried out from 09:00 to 11:30 in the growth chamber under the following conditions: photon flux density of $500 \mu \mathrm{mol} \mathrm{m} \mathrm{m}^{-2} \mathrm{~s}^{-1}$, leaf temperature of $30^{\circ} \mathrm{C}$, relative humidity of $60 \%$, and $\mathrm{CO}_{2}$ concentration of $395 \mu \mathrm{mol} \mathrm{mol}^{-1}$.

2.3. Fatty Acid Composition. Total lipids were extracted by using a method of Folch et al. [24] with some modification. Fresh leaves $(2 \mathrm{~g})$ were ground in $50 \mathrm{~mL}$ of cold isopropanol and mixed thoroughly. After filtration, the residue was extracted for $30 \mathrm{~min}$ in $50 \mathrm{~mL}$ of chloroform/methanol $(2: 1$, $\mathrm{v} / \mathrm{v})$ and refiltered. The filtrate from the first fraction was evaporated in vacuum to remove isopropanol and then dissolved in $30 \mathrm{~mL}$ of chloroform-methanol $(2: 1, \mathrm{v} / \mathrm{v})$. The two collected organic phases were mixed, added with $10 \mathrm{~mL}$ of $0.2 \mathrm{M}$ sodium phosphate buffer, and vortexed for $10 \mathrm{~min}$. The mixture was extracted and dried under nitrogen; the residue was dissolved in hexane and transesterified with $0.5 \mathrm{M}$ sodium methoxide for $20 \mathrm{~min}$ at $50^{\circ} \mathrm{C}$ following the method of Zwiazek and Shay [25]. The reaction was stopped by the addition of glacial acetic acid and water. Known amounts of n-octacosane were also added as an internal standard before transesterification. The hexane phase containing the fatty acid methyl esters was collected for quantification on a $6890 \mathrm{~N}$ gas chromatograph (Aligent, Wilmington, USA), and the parameters were set partially according to Guo et al. [26]. Specifically, $2 \mu \mathrm{L}$ of sample was injected with hydrogen as the carrier gas at a flow rate of $2 \mathrm{~mL} \mathrm{~min}^{-1}$ and injection temperature of $250^{\circ} \mathrm{C}$. The column temperature was initially set at $50^{\circ} \mathrm{C}$ for $6 \mathrm{~min}$ and then increased at $12^{\circ} \mathrm{C} \mathrm{min}^{-1}$ to $170^{\circ} \mathrm{C}$ and held for $25 \mathrm{~min}$ and finally decreased at $4^{\circ} \mathrm{C} \mathrm{min}{ }^{-1}$ to $24^{\circ} \mathrm{C}$ and held for $30 \mathrm{~min}$. Flame ionization detector (FID) temperature was $250^{\circ} \mathrm{C}$. The flow rates of air and nitrogen makeup gas were $300 \mathrm{~mL} \mathrm{~min}^{-1}$ and $30 \mathrm{~mL} \mathrm{~min}^{-1}$, respectively.

2.4. Leaf Chl Content. About $0.1 \mathrm{~g}$ of leaf tissues were ground in a mortar and pestle with $10 \mathrm{~mL}$ of $80 \%$ chilled acetone. The homogenate was centrifuged at $1500 \times \mathrm{g}$ for $5 \mathrm{~min}$. The resulting supernatant was collected and mixed with $10 \mathrm{~mL}$ of $80 \%$ acetone and its absorbance at $663 \mathrm{~nm}$ and $645 \mathrm{~nm}$ was measured on a $U V-1800$ spectrophotometer (Shimadzu, Tokyo, Japan). Chl content was calculated according to the method by Knudson et al. [27].

2.5. Leaf MDA Content. Fresh leaf or root tissues $(0.2 \mathrm{~g})$ were ground in liquid nitrogen in a mortar; then $2 \mathrm{~mL}$ of phosphate buffer ( $\mathrm{pH}$ 7.8) was added and the homogenate was transferred into a $25 \mathrm{~mL}$ test tube. The mortar was rinsed twice with $0.05 \mathrm{M}$ phosphate buffer $(\mathrm{pH} 7.8)$ and the washed buffer solution was added to the test tube. After addition of $5 \mathrm{~mL}$ of $55 \mathrm{mM}$ thiobarbituric acid, the tube was shaken. The tube was heated in a water bath at $100^{\circ} \mathrm{C}$ for $10 \mathrm{~min}$. Then after cooling, the tube was centrifuged and the absorbance of the supernatant at 532,600, and $450 \mathrm{~nm}$ was measured on the UV1800 spectrophotometer according to the method of Wilbur et al. [28].

2.6. ATPase Activity. Fresh root tissues ( $0.5 \mathrm{~g})$ were ground in a chilled mortar with $5 \%(\mathrm{w} / \mathrm{v})$ polyvinylpyrrolidone and then homogenized with $1.2 \mathrm{~mL}$ of $100 \mathrm{mM}$ potassium phosphate buffer ( $\mathrm{pH} 7.0$ ) containing $1 \mathrm{mM}$ EDTA and $1 \%$ Triton X-100. The homogenate was centrifuged at $13000 \times \mathrm{g}$ and $4^{\circ} \mathrm{C}$ for $20 \mathrm{~min}$, and the supernatant was used for ATPase and acid phosphatase assays.

ATPase hydrolysis assay was performed as described by Kim and Weber [29]. The enzyme extract $(1 \mathrm{~mL})$ was mixed with $4 \mathrm{~mL}$ of a reaction mixture containing $50 \mathrm{mM}$ Tris $\mathrm{HCl}$ (pH 7.2), 0.4 M sucrose, $3.0 \mathrm{mM}$ ATP, and $3.0 \mathrm{mM}$ $\mathrm{MgCl}_{2}$ and incubated at $38^{\circ} \mathrm{C}$ for $30 \mathrm{~min}$. The reaction was terminated by adding $0.4 \mathrm{~mL}$ of $30 \%$ trichloroacetic acid. ATPase activity was determined by measuring the release of inorganic phosphate [30].

2.7. Acid Phosphatase Activity. To initiate the phosphatase reaction, $1 \mathrm{~mL}$ of enzyme extract was added to $3 \mathrm{~mL}$ of a mixture containing $50 \mathrm{mM}$ sodium acetate buffer ( $\mathrm{pH} 5.0$ ), $3 \mathrm{mM}$ disodium p-nitrophenyl phosphate, and $1 \mathrm{mM}$ dithiothreitol. After incubation at $25^{\circ} \mathrm{C}$ for $15 \mathrm{~min}$, the reaction was terminated by the addition of $1.0 \mathrm{~mL}$ of $0.4 \mathrm{M} \mathrm{NaOH}$. The absorbance of the mixture was measured at $410 \mathrm{~nm}$, with a reaction terminated at $t=0$ serving as a control, in accordance with the method of Ciereszko et al. [31].

2.8. F Concentration. Leaf or root powder $(0.2 \mathrm{~g})$ was digested in $4 \mathrm{~mL}$ of concentrated nitric acid in an $M D S-8$ microwave 


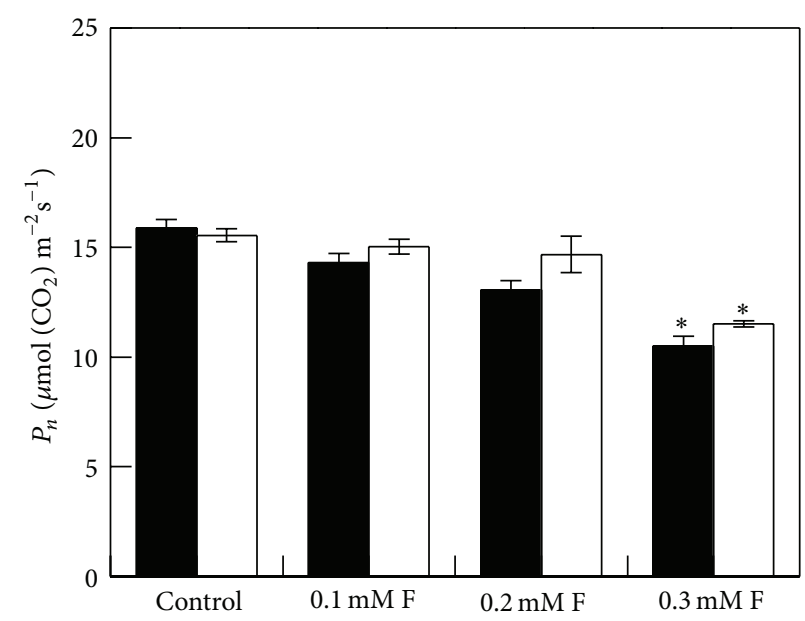

(a)

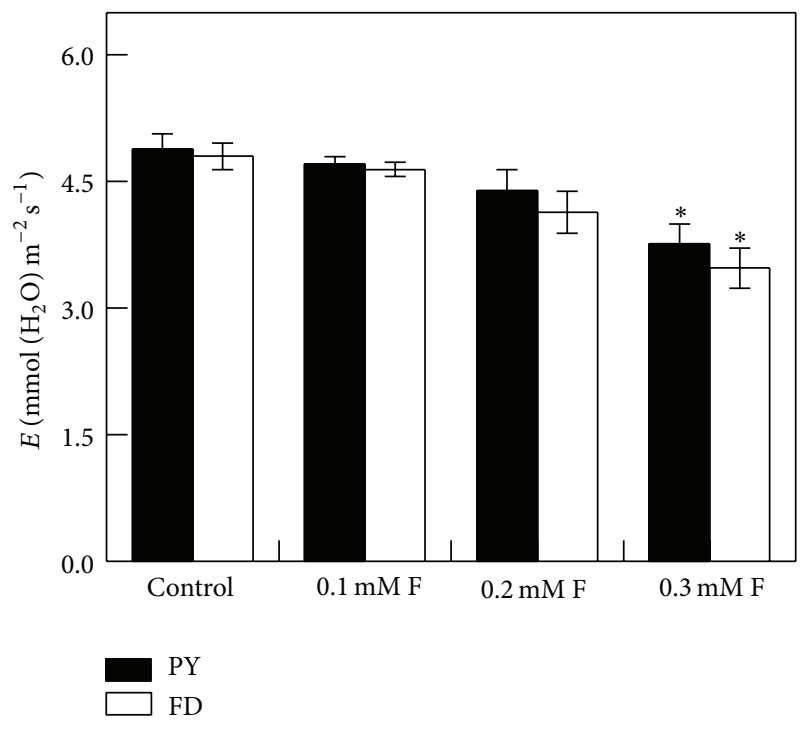

(c)

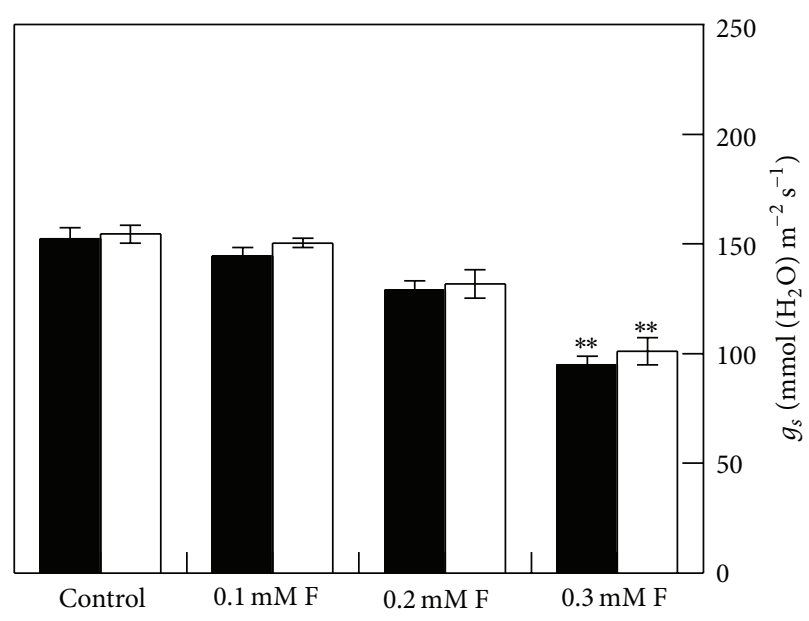

(b)

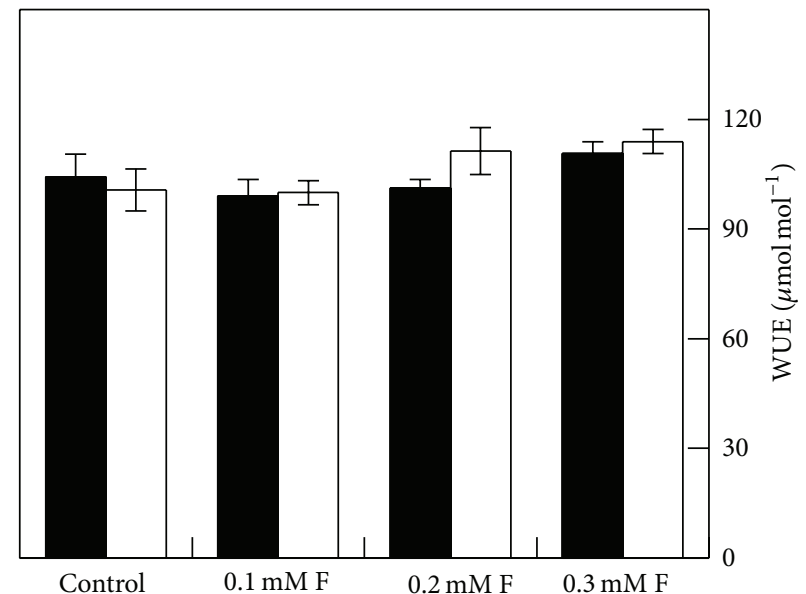

PY

FD

(d)

Figure 1: (a) Net photosynthetic rate $\left(P_{n}\right)$; (b) stomatal conductance $\left(g_{s}\right)$; (c) leaf transpiration $(E)$; and (d) water use efficiency (WUE) after 2 weeks of treatments. Data are expressed as mean \pm SD $(n=4)$. PY: "Pingyangtezao" tea cultivar; FD: "Fudingdabai" tea cultivar. ${ }^{*}\left({ }^{* *}\right)$ indicates significant difference compared with the control at $P<0.05(P<0.01)$ according to Fisher's $F$ test.

digestion device (Sineo, Shanghai, China) set at $120^{\circ} \mathrm{C}$ for $2 \mathrm{~min}$ and $180^{\circ} \mathrm{C}$ for $2 \mathrm{~min}$. The digested liquid was transferred into a $25 \mathrm{~mL}$ volumetric flask and diluted to volume with deionized water. After filtration through Whatman no. 40 filter paper, the filtrate was used for ion detection with a Dual Star F ion selective electrode (Thermo Fisher, Swedesboro, USA).

2.9. Histological Observation. Newly expanded leaves were used for histological observation. Procedures used for obtaining ultrathin sections and section staining were described in detail by Foster [32]. Ultrathin sections stained by toluidine blue (0.1\%) were observed with an Axio Imager A1 light microscope (Zeiss, Shanghai, China).
2.10. Statistical Analyses. All measurements were performed four times, and the data were expressed as means \pm standard deviations (SD). All collected data were subjected to analysis of variance using OriginPro 8.5.1. Significant level at $P<0.05$ was calculated using Fisher's $F$ test.

\section{Results}

3.1. Photosynthetic Parameters and WUE. $P_{n}$ (Figure 1(a)), $g_{s}$ (Figure 1(b)), and $E$ (Figure 1(c)) decreased after F treatments in both cultivars, but significant changes $(P<0.05)$ were only observed in $0.3 \mathrm{mM} \mathrm{F}$ treatment. WUE (Figure $1(\mathrm{~d})$ ) increased in both PY and FD after F treatments but was generally higher in FD than in PY. 
TABLE 1: Fatty acid composition in leaves of PY and FD after 2 weeks of fluoride (F) treatments. Contents are given as percentage of total fatty acid weight. Data are the mean of four replicates. Minor fatty acids less than $1 \%$ of the total amount are not shown. Fatty acids are abbreviated as the number of carbon atoms followed by the number of double bonds in the fatty acid.

\begin{tabular}{|c|c|c|c|c|c|c|c|c|}
\hline \multirow{2}{*}{ Fat acid } & \multicolumn{4}{|c|}{ FD } & \multicolumn{4}{|c|}{ PY } \\
\hline & Control & $0.1 \mathrm{mM} \mathrm{F}$ & $0.2 \mathrm{mM} \mathrm{F}$ & $0.3 \mathrm{mM} \mathrm{F}$ & Control & $0.1 \mathrm{mM} \mathrm{F}$ & $0.2 \mathrm{mM} \mathrm{F}$ & $0.3 \mathrm{mM} \mathrm{F}$ \\
\hline $16: 0$ & 19.2 & 19.3 & 21.4 & $24.6^{*}$ & 20.3 & 21.1 & 22.4 & $25.8^{*}$ \\
\hline $16: 1$ & 3.2 & 2.5 & 2.4 & 2.7 & 2.8 & 3.1 & 3.2 & 3.5 \\
\hline $16: 3$ & 4.1 & 3.4 & 4.8 & 4.3 & 5.8 & 6.3 & 5.7 & 4.0 \\
\hline $18: 0$ & 4.3 & 4.9 & 5.6 & $6.8^{*}$ & 7.1 & 7.5 & 8.4 & $9.2^{*}$ \\
\hline $18: 1$ & 8.3 & 8.2 & 7.1 & 6.6 & 7.3 & 6.8 & 5.9 & $4.2^{*}$ \\
\hline $18: 2$ & 11.5 & 13.5 & 12.5 & 13.7 & 15.6 & 13.9 & 14.4 & 15.8 \\
\hline $18: 3$ & 41.1 & 40.6 & $38.4^{*}$ & $36.1^{*}$ & 32.6 & 31.8 & 31.9 & 30.2 \\
\hline $20: 0$ & 7.4 & 6.1 & 5.2 & $3.8^{*}$ & 7.6 & 8.3 & 6.5 & $4.5^{*}$ \\
\hline
\end{tabular}

${ }^{*}$ Indicates a significant difference compared with the control at $P<0.05$ according to Fisher's $F$ test.

PY: "Pingyangtezao" tea cultivar; FD: "Fudingdabai" tea cultivar.

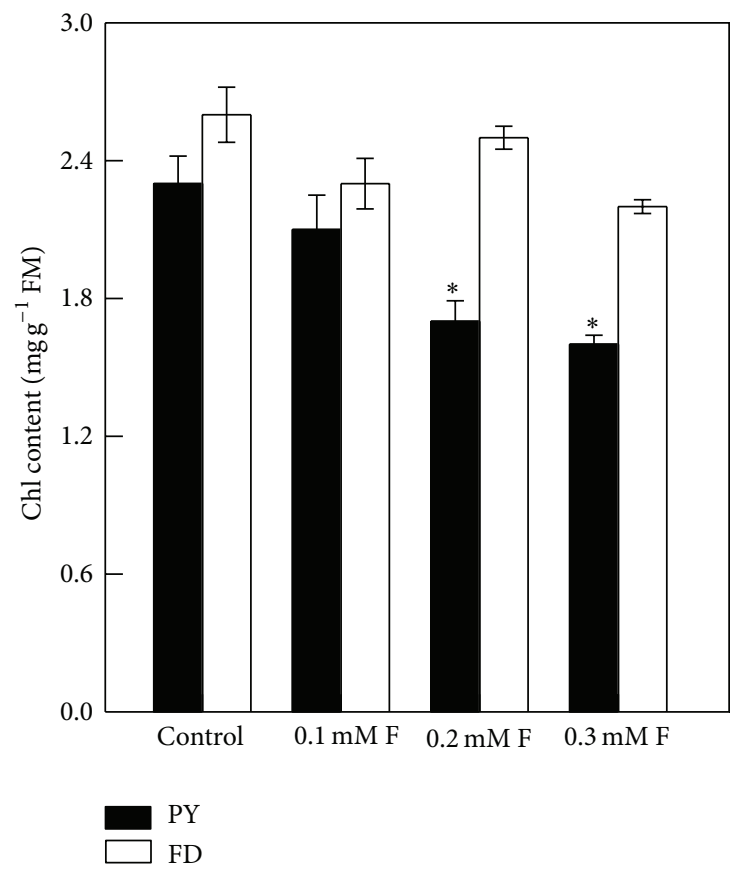

(a)

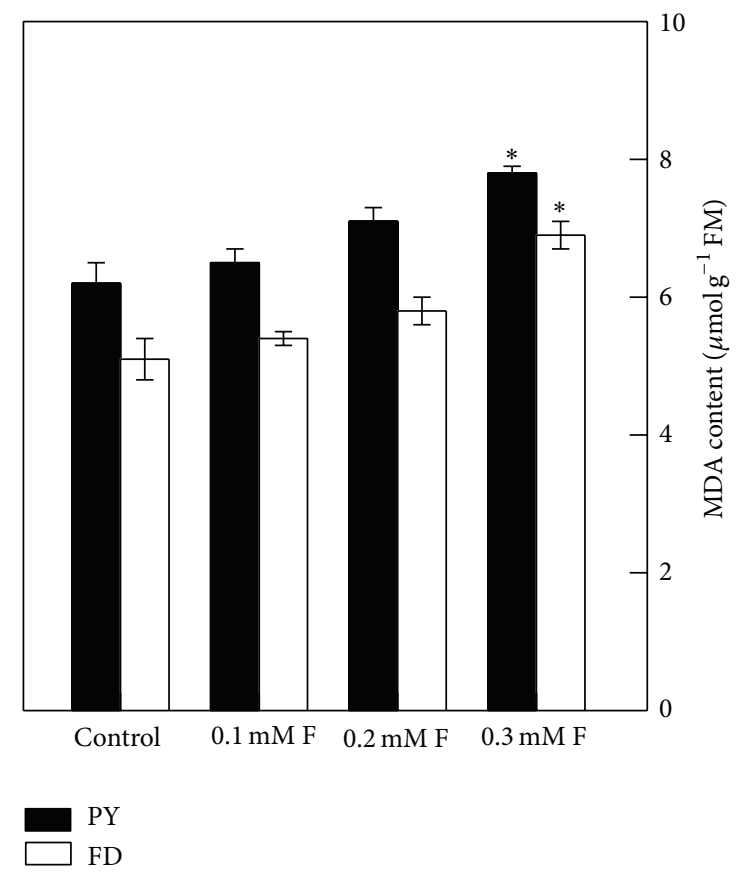

(b)

FIGURE 2: (a) Chlorophyll (Chl) content and (b) malondialdehyde (MDA) content in leaves of PY and FD seedlings after 2 weeks of treatment. Data are expressed as mean \pm SD $(n=4)$. PY: "Pingyangtezao" tea cultivar; FD: "Fudingdabai" tea cultivar. ${ }^{*}$ indicates significant difference compared with the control here at $P<0.05$ according to Fisher's $F$ test.

3.2. Changes in Fatty Acid Composition in Leaves. The proportions of palmitic acid (16:0) and stearic acid (18:0) increased significantly in both cultivars after $0.3 \mathrm{mM} \mathrm{F}$ treatment (Table 1). The contents of these two acids were higher in PY than in FD. However, the proportions of arachic acid $(20: 0)$ decreased significantly in PY and FD after the same F treatment, but arachic acid contents in PY were higher than in FD. With respect to unsaturated fatty acids such as oleic acid (18:1) and linolenic acid (18:3), the responses of the two cultivars differed. Contents of linolenic acid (18:3) in FD significantly decreased after $0.2 \mathrm{mM}$ and $0.3 \mathrm{mM}$ treatments, while the content of oleic acid $(18: 1)$ in PY decreased only after $0.3 \mathrm{mM}$ treatment.

3.3. Leaf Chl and MDA Contents. While Chl content in PY significantly decreased after 0.2 and $0.3 \mathrm{mM} \mathrm{F}$ treatments, no significant changes were observed in FD (Figure 2(a)). MDA contents in both PY and FD significantly increased after $0.3 \mathrm{mM}$ treatment (Figure 2(b)). In the control plants, Chl content was higher in FD than in PY, whereas MDA content was lower in FD than in PY. 


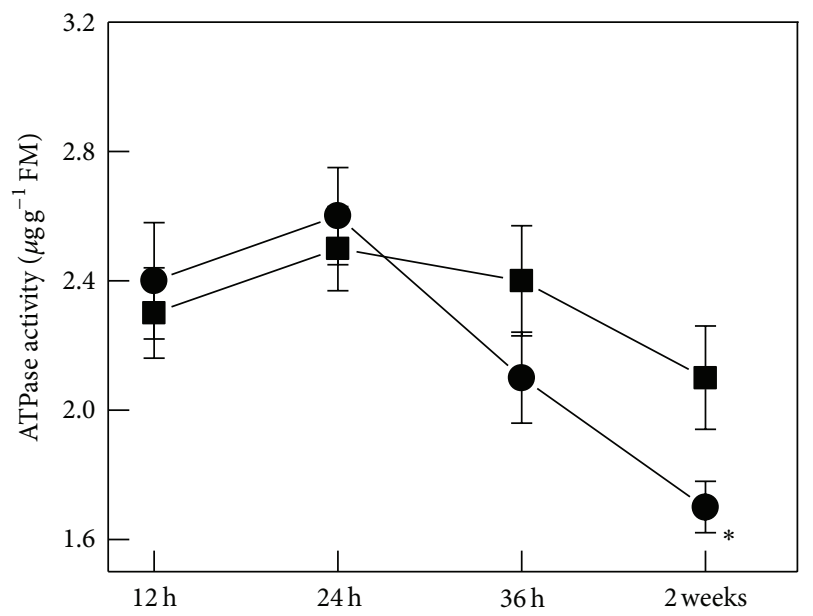

(a)

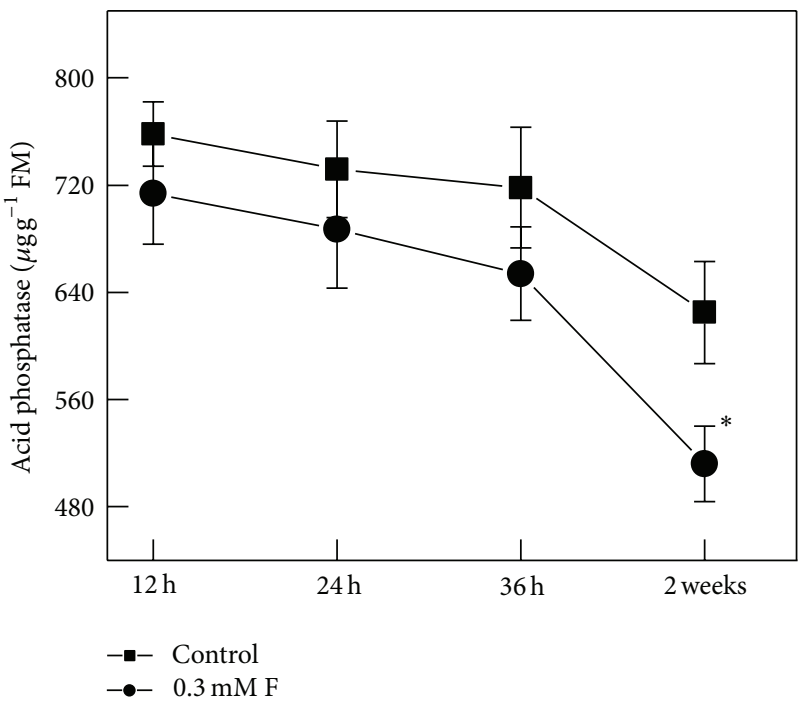

(c)

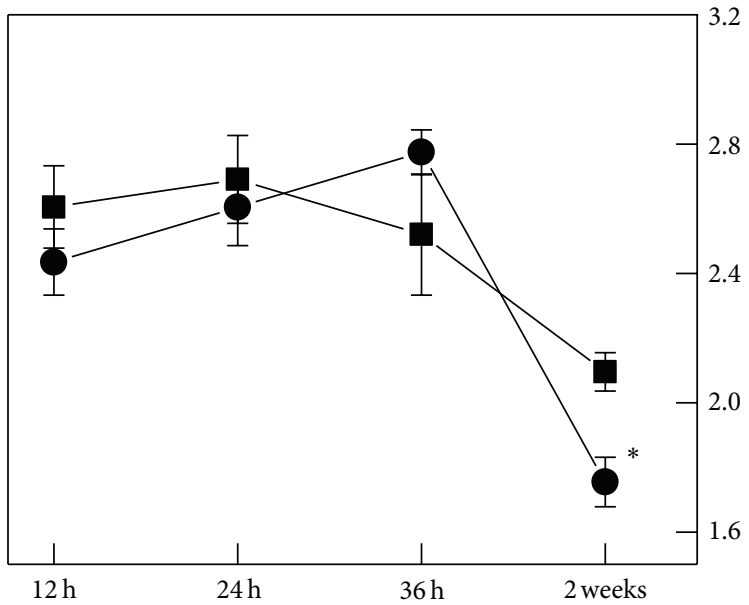

(b)

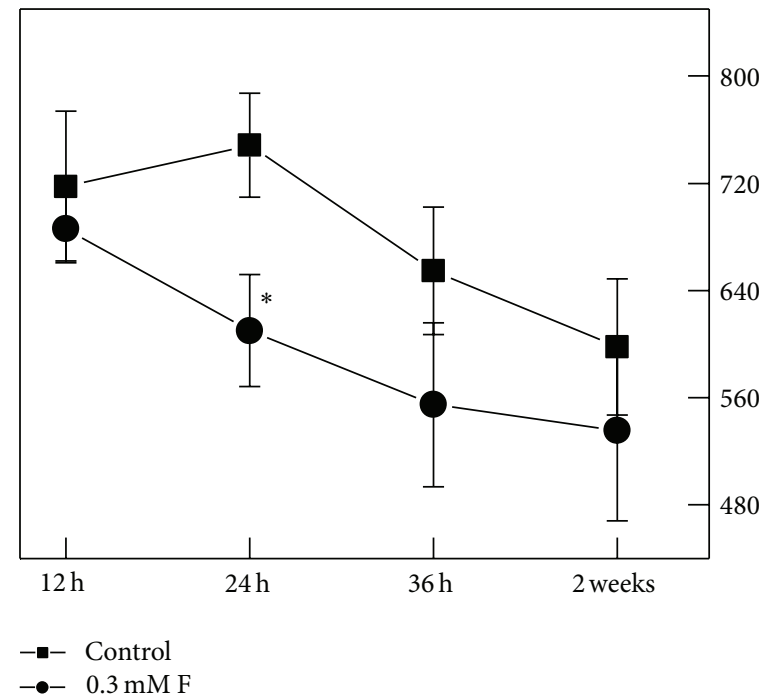

(d)

FIGURE 3: ATPase and acid phosphatase activities in roots of PY and FD seedlings after $12 \mathrm{~h}, 24 \mathrm{~h}, 36 \mathrm{~h}$, and 2-week exposure to $0.3 \mathrm{mM}$ fluoride (F). Data are expressed as means \pm SD $(n=4)$. PY: "Pingyangtezao" tea cultivar; FD: "Fudingdabai" tea cultivar. (a) ATPase activity in PY; (b) ATPase activity in FD; (c) acid phosphatase activity in PY; (d) acid phosphatase activity in FD. ${ }^{*}$ indicates significant difference compared with the control here at $P<0.05$ according to Fisher's $F$ test.

3.4. ATPase and Acid Phosphatase Activities. Temporal changes of ATPase and acid phosphatase activities were recorded in roots after F treatments. ATPase activity in PY increased after $24 \mathrm{~h}$ of $0.3 \mathrm{mM} \mathrm{F}$ treatment and then significantly decreased after 2 weeks (Figure 3(a)). A similar changing pattern was observed in FD: an increase after $36 \mathrm{~h}$ treatment and a decline after a longer treatment of 2 weeks (Figure 3(b)). Compared with the control plants, acid phosphatase activity significantly decreased in PY after 2-week treatment (Figure 3(c)) but significantly decreased in FD only after $24 \mathrm{~h}$ F treatment (Figure 3(d)).

3.5. Changes in F Concentration. Compared with the control plants, $\mathrm{F}$ concentrations in roots and leaves of both PY and FD increased significantly in all F treatments (Table 2).
F concentrations in roots and leaves of PY were 1.2-1.6 times higher than in FD. A similar trend was observed in the control plants, with 17-25\% increase in PY, compared with FD.

3.6. Histological Observation. $\mathrm{F}$ treatment induced more cell injury in the leaf midrib region of PY (Figure 4(a)) than in that of FD (Figure 4(b)), as evidenced by brown coloration upon histochemical staining. Compared with PY (Figure 4(c)), the arrangement of leaf lamina spongy mesophyll was more compact in FD (Figure 4(d)).

\section{Discussion}

Photosynthesis can be limited by two major processes: decrease of stomatal conductance and impairment of leaf 
TABLE 2: Fluoride (F) accumulation in roots and leaves of PY and FD after 2-week fluoride treatments ( $\left.\mathrm{mg} \mathrm{kg}^{-1} \mathrm{DM}\right)$. Data are expressed as means $\pm \mathrm{SD}(n=4)$.

\begin{tabular}{|c|c|c|c|c|}
\hline \multirow{2}{*}{ Treatment } & \multicolumn{2}{|c|}{ PY } & \multicolumn{2}{|c|}{ FD } \\
\hline & Root & Leaf & Root & Leaf \\
\hline Control & $0.5 \pm 0.05$ & $95 \pm 4$ & $0.4 \pm 0.04$ & $81 \pm 3$ \\
\hline $0.1 \mathrm{mM} \mathrm{F}$ & $2.2 \pm 0.2^{* * *}$ & $167 \pm 8^{* * *}$ & $1.4 \pm 0.1^{* * *}$ & $124 \pm 6^{* * *}$ \\
\hline $0.2 \mathrm{mM} \mathrm{F}$ & $3.6 \pm 0.3^{* * *}$ & $210 \pm 10^{* * *}$ & $2.1 \pm 0.2^{* * *}$ & $177 \pm 9^{* * *}$ \\
\hline $0.3 \mathrm{mM} \mathrm{F}$ & $5.6 \pm 0.4^{* * *}$ & $269 \pm 11^{* * *}$ & $3.4 \pm 0.3^{* * *}$ & $226 \pm 14^{* * *}$ \\
\hline
\end{tabular}

${ }^{* * *}$ Indicates significant difference compared with the control at $P<0.001$ according to Fisher's $F$ test.

PY: "Pingyangtezao" tea cultivar; FD: "Fudingdabai" tea cultivar.

photochemistry [33]. Another inhibitor of photosynthesis is the low plant water status, which can trigger stomatal closure [34]. Photosynthesis has been observed to decrease in Picea and Pinus after sodium fluoride treatment [34-36]. In our study, $P_{n}$ (Figure 1(a)), $g_{s}$ (Figure 1(b)), and $E$ (Figure 1(c)) in both PY and FD significantly decreased after $0.3 \mathrm{mM}$ $F$ treatment, but the effects of $F$ treatment were different between the two varieties. Under F treatments, FD had higher $P_{n}, g_{s}$, and WUE (Figure 1(d)) but lower $E$ than PY. The decreased photosynthetic activity observed after F treatment may be the result of lowered $g_{s}$. Several studies show that F treatment can inhibit hydraulic conductivity in root or shoot $[14,37]$, which might affect water balance in guard cells and induce stomatal closure. The decrease in $E$ after $\mathrm{F}$ treatment observed in our study may also be ascribed to the lower $g_{s}$. The higher $P_{n}$ in FD compared with PY may be related to FD's higher WUE (Figure 1(d)) in leaf and lower E (Figure 1(c)). Maintenance of higher $P_{n}$ and WUE and lower water loss by transpiration in FD than in PY indicates that FD is more tolerant to $\mathrm{F}$.

Chl content is an important photosynthetic parameter, but it may not be directly correlated with photosynthesis. In this study, a higher leaf Chl content in FD control plants (Figure 2(a)) was not accompanied by a higher photosynthetic rate (Figure 1(a)) compared with PY control plants. This finding is consistent with observations in F-treated aspen seedlings [14]. While $\mathrm{F}$ treatment can reduce the leaf Chl content in cereals and aspen [14, 38], no obvious effect has been observed in Salicornia or Chloris $[39,40]$. In our study, Chl content did not change significantly in FD with increasing F concentration but decreased significantly in PY. The effect of $\mathrm{F}$ treatment on $\mathrm{Chl}$ is not clear. Chl content was always higher in FD than in PY either with or without F treatment. These results might be explained by the anatomical structure of leaves. Mesophyll cells serve as storage areas for chlorophyll, and their concentration in laminae may reflect Chl content in leaves; we observed accordingly that the mesophyll cell layer in FD (Figure 4(d)) was tighter and thicker than in PY (Figure 4(c)). It may also be concluded that the effects of $\mathrm{F}$ treatment on $\mathrm{Chl}$ content differed between the two cultivars.

Lipids are esters of fatty acids and alcohols and comprise a large group of structurally distinct organic compounds that include fats, waxes, phospholipids, and glycolipids [41]. As major components of membrane lipids, fatty acids play an important role in maintaining normal physiological cell function under environmental stress, including temperature, salt, chemicals, ions, pressure, and oxidative stress [42]. $\mathrm{F}$ treatment can induce changes in lipid bilayer structure and alter the proportions of fatty acids [16]. Increase in palmitic acid content and decrease in linoleic acid content were observed in lipid fractions of F-treated Sphagnum and Pinus $[16,43]$. In our study, the proportions of shorter chain and saturated fatty acids increased, while those of longer chain and unsaturated fatty acids decreased in both cultivars under F treatments (Table 2). These results appear to support the hypothesis of Simolal and Koskimies-Soininen (1980) [43] that $\mathrm{F}$ ions can inhibit the lengthening of fatty acid chains. The proportions of fatty acids in the two cultivars were different, but this might be a consequence of different lipid peroxidation levels. F can stimulate peroxidase and catalase activities in plants $[16,44,45]$, inducing production of saturated fatty acids and MDA. In our study, MDA contents increased in both F-treated cultivars but were higher in PY than in FD plants (Figure 2(b)). Consistently, higher increases in levels of saturated fatty acids (i.e., palmitic acid and stearic acid) were observed in PY compared with FD. These differences may be ascribed to the more intensified peroxidation in PY than in FD under F treatment.

ATPase and acid phosphatase are widely distributed in different plant species and mainly localized in plasma membranes and vacuoles [46]. They are involved in the key metabolic functions of plants, such as growth, mineral nutrition, and transportation of stored metabolites [25]. F is known to be an inhibitor of activities of ATPase [47] and acid phosphatase $[16,48]$. Though no changes in acid phosphatase activity were observed in plants exposed to $\mathrm{F}$ pollution by Yee Meiler (1975) [49], we observed decreases, as compared with controls, in ATPase and acid phosphatase activities in roots of both varieties after 2 weeks of $0.3 \mathrm{mM}$ F treatment. A shorter treatment duration led to elevated ATPase activity in both varieties, but no increased acid phosphatase activity was recorded. This short-time activated enzyme activity may be due to that some other ions or organic anions combine with the enzyme to protect it from $\mathrm{F}$ inhibition.

In plants, $F$ accumulation occurs mainly in mature leaves and may cause visual symptoms such as leaf tip and marginal chlorosis or necrosis [50]. The mechanism behind F toxic symptoms has not been fully elucidated. F-induced injury has been observed in mesophyll cell membranes and abundant deposits of lipid material have been found near plasmalemma, tonoplast, chloroplast, and mitochondrial 


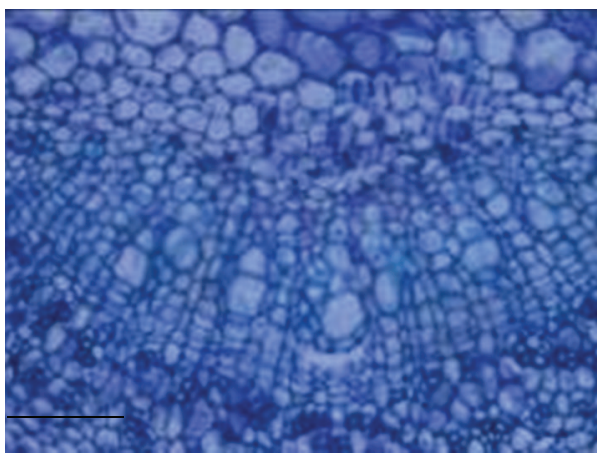

(a)

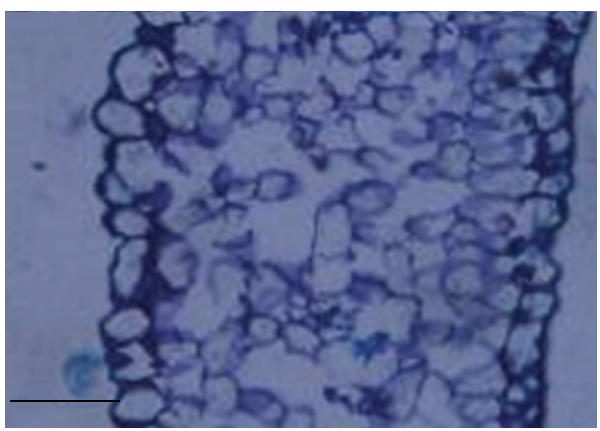

(c)

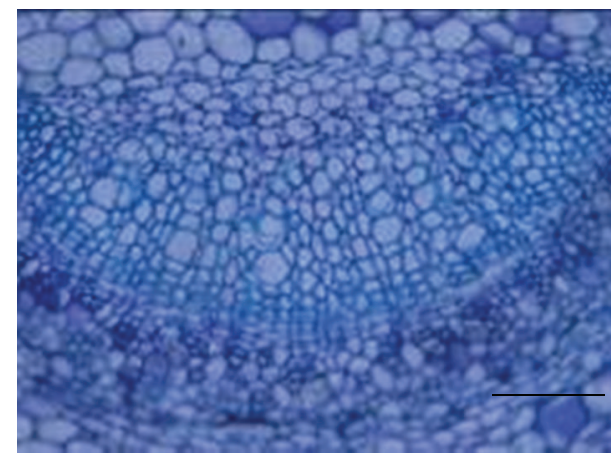

(b)

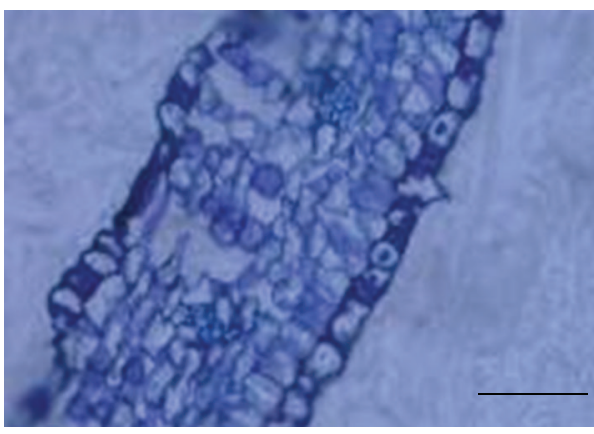

(d)

Figure 4: Comparison of root and leaf transections between PY and FD after 2 weeks of $0.3 \mathrm{mM}$ fluoride (F) treatment. (a) and (c) represent midrib regions and leaf lamina, respectively, in PY; (b) and (d) represent midrib regions and leaf lamina, respectively, in FD. Scale bar = $100 \mu \mathrm{m}$ in (a) and (b); scale bar $=25 \mu \mathrm{m}$ in (c) and (d). PY: "Pingyangtezao" tea cultivar; FD: "Fudingdabai" tea cultivar.

membranes [16, 51], so cell membranes, are possible sites of F-induced damage. In this study, higher F concentrations (Table 2) were observed in PY leaves and roots, which may lead to more cell injury in the leaf midrib region than in FD (Figure 4).

In conclusion, $\mathrm{F}$ treatment can decrease photosynthesis and the activities of ATPase and acid phosphatase, change fatty acid composition, and cause anatomical structure injury in tea plants. The cultivar FD is more tolerant to F treatment, as it is characterized by better maintenance of photosynthesis and enzyme activity, better control of $\mathrm{F}$ absorption and membrane lipid degradation, and thus more efficient protection of metabolic processes and organic structure.

\section{References}

[1] M. Jakovljevic, S. Blagojevic, and S. Antic-Mladenovic, "Fluorine content in soils of northern Pomoravlje," Journal of Agricultural Sciences, vol. 47, pp. 121-128, 2002.

[2] C. Haidouti, A. Chronopoulou, and J. Chronopoulos, "Effects of fluoride emissions from industry on the fluoride concentration of soils and vegetation," Biochemical Systematics and Ecology, vol. 21, no. 2, pp. 195-208, 1993.

[3] B. L. Skjelkvåle, "Water chemistry in areas with high deposition of fluoride," Science of the Total Environment, vol. 152, no. 2, pp. 105-112, 1994.

[4] W. Czarnowski, K. Wrzesniowska, and J. Krechniak, "Fluoride in water, urine and egg shells as an indicator of environmental contamination," Fluoride, vol. 27, no. 3, pp. 141-144, 1994.
[5] S. J. Cronin, V. Manoharan, M. J. Hedley, and P. Loganathan, "Fluoride: a review of its fate, bioavailability, and risks of fluorosis in grazed-pasture systems in New Zealand," New Zealand Journal of Agricultural Research, vol. 43, no. 3, pp. 295321, 2000.

[6] S.-C. C. Lung, H.-W. Cheng, and C. B. Fu, "Potential exposure and risk of fluoride intakes from tea drinks produced in Taiwan," Journal of Exposure Science and Environmental Epidemiology, vol. 18, no. 2, pp. 158-166, 2008.

[7] P. B. Maithani, R. Gurjar, R. Banerjee, B. K. Balaji, S. Ramachandran, and R. Singh, "Anomalous fluoride in groundwater from western part of Sirohi district, Rajasthan and its crippling effects on human health," Current Science, vol. 74, no. 9, pp. 773-777, 1998.

[8] P. J. Peterson, "Assessment of exposure to chemical contaminants in water and food," Science of the Total Environment, vol. 168 , no. 2, pp. 123-129, 1995.

[9] E. Malinowska, I. Inkielewicz, W. Czarnowski, and P. Szefer, "Assessment of fluoride concentration and daily intake by human from tea and herbal infusions," Food and Chemical Toxicology, vol. 46, no. 3, pp. 1055-1061, 2008.

[10] D. P. Stevens, M. J. Mclaughlin, P. J. Randall, and G. Keerthisinghe, "Effect of fluoride supply on fluoride concentrations in five pasture species: levels required to reach phytotoxic or potentially zootoxic concentrations in plant tissue," Plant and Soil, vol. 227, no. 1-2, pp. 223-233, 2000.

[11] C. Li and D. Ni, "Effect of fluoride on chemical constituents of tea leaves," Fluoride, vol. 42, no. 3, pp. 237-243, 2009. 
[12] B. F. Sant'Anna-Santos, A. A. Azevedo, L. C. Silva, and M. A. Oliva, "Diagnostic and prognostic characteristics of phytotoxicity caused by fluoride on Spondias dulcis Forst. F. (Anacardiaceae)," Annals of the Brazilian Academy of Sciences, vol. 84, pp. 689-702, 2012.

[13] X. Zhang, H. Gao, Z. Zhang, and X. Wan, "Influences of different ion channel inhibitors on the absorption of fluoride in tea plants (Camellia sinesis L.)," Plant Growth Regulation, vol. 69, pp. 99-106, 2013.

[14] M. Kamaluddin and J. J. Zwiazek, "Fluoride inhibits root water transport and affects leaf expansion and gas exchange in aspen (Populus tremuloides) seedlings," Physiologia Plantarum, vol.117, no. 3, pp. 368-375, 2003.

[15] M. H. Yu and G. W. Miller, "Effect of fluoride on the respiration of leaves from higher plants," Plant and Cell Physiology, vol. 8, pp. 483-493, 1967.

[16] J. J. Zwiazek and J. M. Shay, "Sodium fluoride induced metabolic changes in jack pine seedlings. I. Effect on gas exchange, water content and carbohydrates," Canadian Journal of Forest Research, vol. 18, no. 10, pp. 1305-1310, 1988.

[17] J. Ruan and M. H. Wong, "Accumulation of fluoride and aluminium related to different varieties of tea plant," Environmental Geochemistry and Health, vol. 23, no. 1, pp. 53-63, 2001.

[18] W. S. Shu, Z. Q. Zhang, C. Y. Lan, and M. H. Wong, "Fluoride and aluminium concentrations of tea plants and tea products from Sichuan Province, PR China," Chemosphere, vol. 52, no. 9, pp. 1474-1482, 2003.

[19] Z. Xie, Z. Chen, W. Sun, X. Guo, B. Yin, and J. Wang, "Distribution of aluminum and fluoride in tea plant and soil of tea garden in Central and Southwest China," Chinese Geographical Science, vol. 17, no. 4, pp. 376-382, 2007.

[20] F. N. Wachira, W. Powell, and R. Waugh, "An assessment of genetic diversity among Camellia sinensis L. (Cultivated tea) and its wild relatives based on randomly amplified polymorphic DNA and organelle-specific STS," Heredity, vol. 78, no. 6, pp. 603-611, 1997.

[21] J.-A. Lai, W.-C. Yang, and J.-Y. Hsiao, "An assessment of genetic relationships in cultivated tea clones and native wild tea in Taiwan using RAPD and ISSR markers," Botanical Bulletin of Academia Sinica, vol. 42, no. 2, pp. 93-100, 2001.

[22] G. N. Amzallag, H. R. Lerner, and A. Poljakoff-mayber, "Interaction between mineral nutrients, cytokinin and gibberellic acid during growth of Sorghum at high NaCI salinity," Journal of Experimental Botany, vol. 43, no. 1, pp. 81-87, 1992.

[23] L. Li, X. Du, and C. He, "Absorption and accumulation characteristics of fluorine in nutrient liquid cultured tea plant," Journal of Sichuan Agriculture University, vol. 26, pp. 59-63, 2008 (Chinese).

[24] J. Folch, M. Lees, and G. H. Sloane Stanley, "A simple method for the isolation and purification of total lipides from animal tissues," The Journal of biological chemistry, vol. 226, no. 1, pp. 497-509, 1957.

[25] J. J. Zwiazek and J. M. Shay, "Sodium fluoride induced metabolic changes in jack pine seedlings. II. Effect on growth, acid phosphatase, cytokinins, and pools of soluble proteins, amino acids, and organic acids," Canadian Journal of Forest Research, vol. 18, no. 10, pp. 1311-1317, 1988.

[26] H. Guo, J. Zhou, J. Luo, H. Tan, and D. Liu, "Determination of the composition of fatty acids from tea seed oil," Journal of Zhejiang University, vol. 36, pp. 212-220, 2010 (Chinese).
[27] L. L. Knudson, T. W. Tibbits, and G. E. Edwards, "Measurement of ozone injury by determination of leaf chlorophyll concentration," Plant Physiology, vol. 60, no. 4, pp. 606-608, 1977.

[28] K. M. Wilbur, F. Bernheim, and O. W. Shapiro, "The thiobarbituric acid reagent as a test for the oxidation of unsaturated fatty acids by various agents," Archives of Biochemistry, vol. 24, no. 2, pp. 305-313, 1949.

[29] C.-K. Kim and D. J. Weber, "Isolation and characterization of adenosine triphosphatase from Salicornia pacifica var. utahensis," Plant and Cell Physiology, vol. 21, no. 5, pp. 755-763, 1980.

[30] T. Ohnishi, R. S. Gall, and M. L. Mayer, "An improved assay of inorganic phosphate in the presence of extralabile phosphate compounds: application to the ATPase assay in the presence of phosphocreatine," Analytical Biochemistry, vol. 69, no. 1, pp. 261-267, 1975.

[31] I. Ciereszko, A. Janonis, and M. Kociakowska, "Growth and metabolism of cucumber in phosphate-deficient conditions," Journal of Plant Nutrition, vol. 25, no. 5, pp. 1115-1127, 2002.

[32] A. S. Foster, "Structure and development of sclereids in the petiole of Camellia japonica L.," Bulletin of the Torrey Botanical Club, vol. 71, pp. 302-326, 1944.

[33] S. N. Shabala, S. I. Shabala, A. I. Martynenko, O. Babourina, and I. A. Newman, "Salinity effect on bioelectric activity, growth, $\mathrm{Na}^{+}$accumulation and chlorophyll fluorescence of maize leaves: a comparative survey and prospects for screening," Australian Journal of Plant Physiology, vol. 25, no. 5, pp. 609-616, 1998.

[34] J. J. Zwiazek and J. M. Shay, "The effects of sodium fluoride on cytoplasmic leakage and the lipid and fatty acid composition of jack pine (Pinus banksiana) seedlings," Canadian Journal of Botany, vol. 66, pp. 535-541, 1988.

[35] M. Kayama, K. Sasa, and T. Koike, "Needle life span, photosynthetic rate and nutrient concentration of Picea glehnii, $P$. jezoensis and $P$. abies planted on serpentine soil in northern Japan," Tree Physiology, vol. 22, no. 10, pp. 707-716, 2002.

[36] D. S. Choi, M. Kayama, H. O. Jin, C. H. Lee, T. Izuta, and T. Koike, "Growth and photosynthetic responses of two pine species (Pinus koraiensis and Pinus rigida) in a polluted industrial region in Korea," Environmental Pollution, vol. 139, no. 3, pp. 421-432, 2006.

[37] P. Gerbeau, G. Amodeo, T. Henzler, V. Santoni, P. Ripoche, and C. Maurel, "The water permeability of Arabidopsis plasma membrane is regulated by divalent cations and $\mathrm{pH}$," Plant Journal, vol. 30, no. 1, pp. 71-81, 2002.

[38] J. Kaur and C. Duffus, "The effect of sodium fluoride on cereal seed germination and seedling growth," Plant Cell and Environment, vol. 12, pp. 155-161, 1989.

[39] A. M. Divan Junior, M. A. Oliva, C. A. Martinez, and J. Cambraia, "Effects of fluoride emissions on two tropical grasses: Chloris gayana and Panicum maximum cv. Colonião," Ecotoxicology and Environmental Safety, vol. 67, no. 2, pp. 247-253, 2007.

[40] M. P. Reddy and M. Kaur, "Sodium fluoride induced growth and metabolic changes in Salicornia brachiata Roxb," Water, Air, and Soil Pollution, vol. 188, no. 1-4, pp. 171-179, 2008.

[41] S. C. Singh, R. P. Sinha, and D.-P. Häder, "Role of lipids and fatty acids in stress tolerance in cyanobacteria," Acta Protozoologica, vol. 41, no. 4, pp. 297-308, 2002.

[42] R. G. Upchurch, "Fatty acid unsaturation, mobilization, and regulation in the response of plants to stress," Biotechnology Letters, vol. 30, no. 6, pp. 967-977, 2008. 
[43] K. Simolal and K. Koskimies-Soininen, "The effect of fluoride on the growth and fatty acid composition of Sphagnumjmbriatum at two temperatures," Plant Physiology, vol. 50, pp. 74-77, 1980.

[44] C. J. Lee, G. W. Miller, and G. W. Welkie, “The effect of hydrogen fluoride and wounding on respiratory enzymes in soybean leaves," International Journal of Air and Water Pollution, vol. 10, pp. 169-181, 1966.

[45] J. I. Gray, "Measurement of lipid oxidation: a review," Journal of the American Oil Chemists' Society, vol. 55, no. 6, pp. 539-546, 1978.

[46] R. B. Lee, "Phosphatase influx and extracellular phosphatase activity in barley roots and rose cells," Physiology News, vol. 109, pp. 141-148, 1988.

[47] K. J. Rakowski, J. J. Zwiazek, and M. J. Sumner, "Hydrogen fluoride effects on plasma membrane composition, ATPase activity and cell structure in needles of eastern white pine (Pinus strobus) seedlings," Trees, vol. 9, no. 4, pp. 190-194, 1995.

[48] A. R. Facanha and L. De Meis, "Inhibition of maize root H+-ATPase by fluoride and fluoroaluminate complexes," Plant Physiology, vol. 108, no. 1, pp. 241-246, 1995.

[49] D. Yee Meiler, "Measurement of phosphatase and esterase activity in Norway spruce needles and birch leaves to detect "hidden" F injury," European Journal of Forest Pathology, vol. 5, no. 6, pp. 329-338, 1975.

[50] J. S. Jacobson, L. H. Weinstein, D. C. McCune, and A. E. Hitchcock, "The accumulation of fluorine by plants," Journal of the Air Pollution Control Association, vol. 16, no. 8, pp. 412-417, 1966.

[51] J. J. Zwiazek and J. M. Shay, "Fluoride- and drought- induced structural alterations of mesophyll and guard cells in cotyledons of jack pine (Pinus banksiana)," Canadian Journal of Botany, vol. 65, pp. 2310-2317, 1987. 


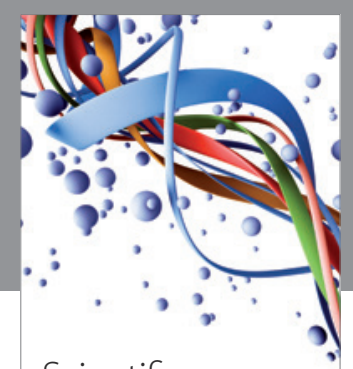

Scientifica
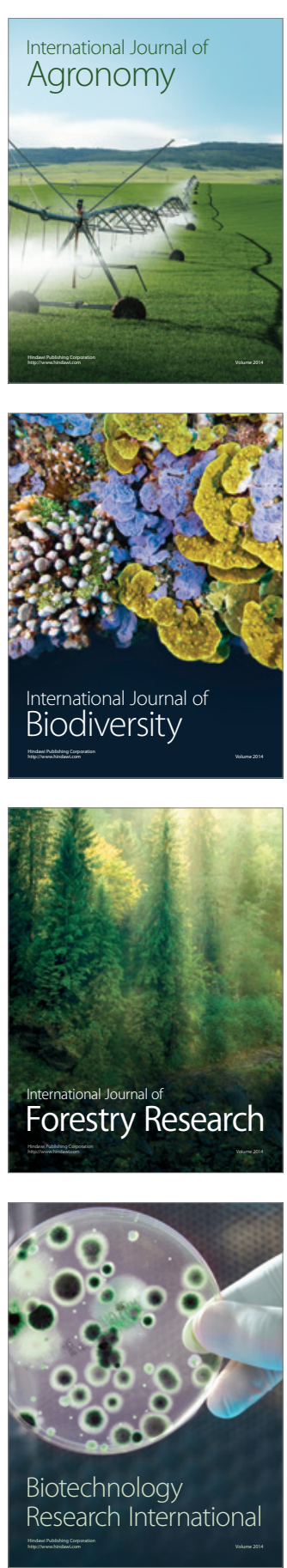
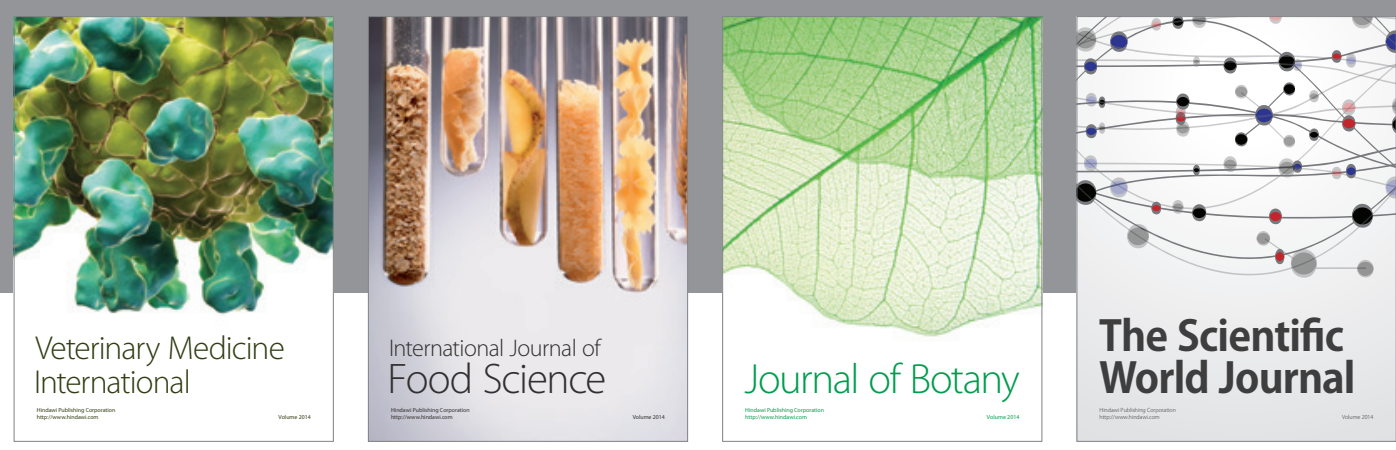

The Scientific World Journal
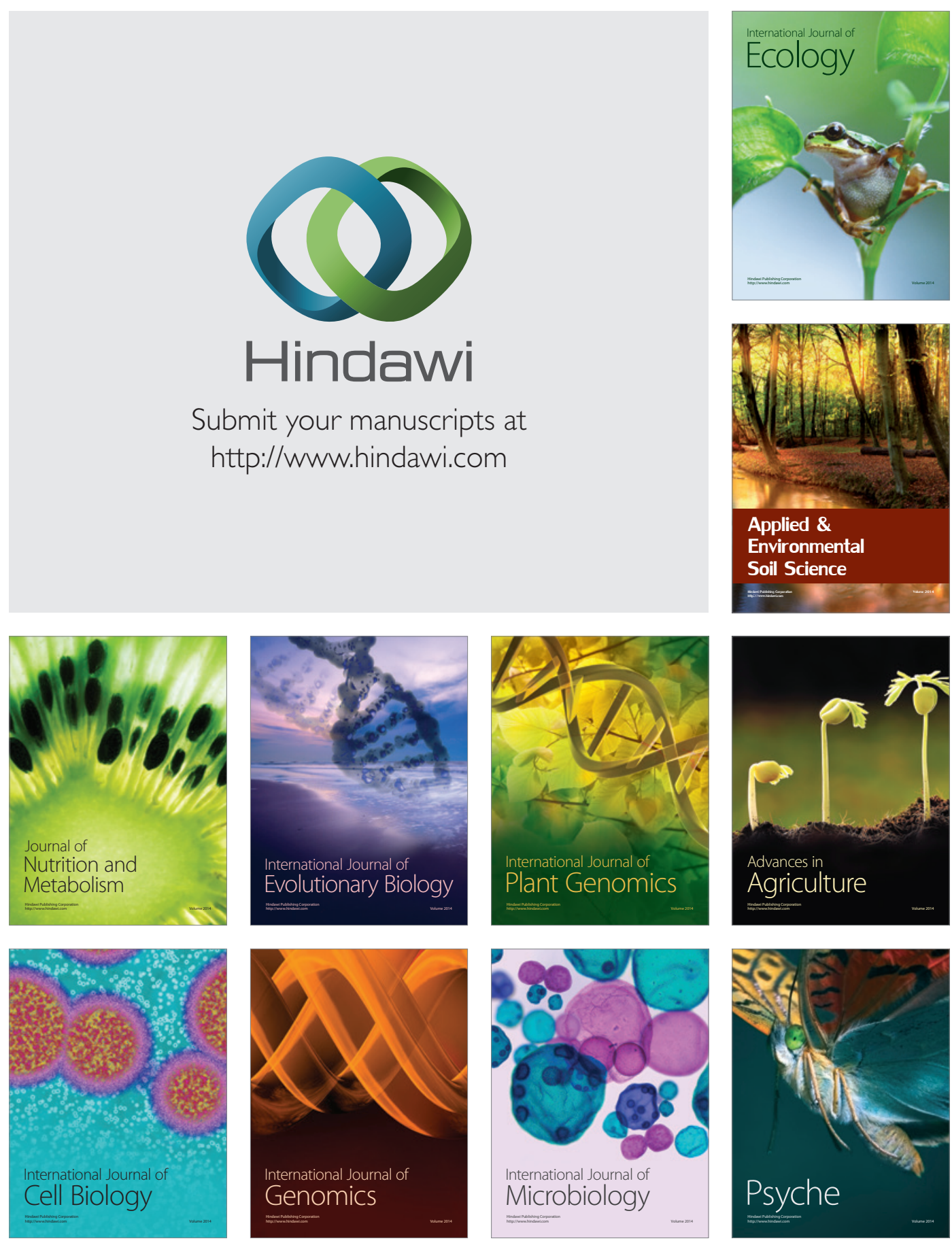